\title{
Sumak Qamaña versus indianismo- katarismo. Una disputa ideológica por el proyecto político de nación en Bolivia
}

\author{
Odín Ávila Rojas ${ }^{1}$
}

Fecha de recepción: 28 de mayo de 2013

Fecha de aprobación: 10 de octubre de 2013

"Las ideas, las ideologías, son, en última instancia, las personas. Quienes las transforman en bellas realidades o las prostituyen".

REINAGA, Fausto. Tesis India

\begin{abstract}
Resumen
Este trabajo tiene por objetivo hacer un análisis y reflexión sobre la disputa ideológica entre el horizonte indianista-katarista y el Vivir Bien o Sumak Qamaña. La finalidad radica en no solo dar a conocer un fenómeno ideológico casi o prácticamente desconocido en las esferas académicas universitarias fuera de las fronteras bolivianas, sino también significa recuperar la discusión central entre indianismos (y katarismos) e indigenismos, es decir, dos maneras opuestas de comprender y plantear la cuestión indígena en América Latina. Ambas representan puntos de partida históricos distintos para pensar y conocer en términos ideológicos al indio como sujeto político que se reactualiza en contextos complejos y contradictorios al interior de la modernidad capitalista en su etapa neoliberal más avanzada.
\end{abstract}

Palabras claves: Indianismo-katarismo, ideología, Sumak Qamaña, Hegemonía, Política.

\begin{abstract}
This work aims to analyse and reflect on the ideological dispute between the indianist-katarist horizon and the Living Well or Sumak Qamaña. It aims not only at presenting an ideological phenomenon hardly known beyond the borders of the Bolivian academic sphere, but it also intends to reposition this main debate on two different understandings of the
\end{abstract}

1 Maestro en Estudios Latinoamericanos por la Universidad Nacional Autónoma de México. Programa de Doctorado en Ciencias Sociales de la Universidad Autónoma Metropolitana - Unidad Xochimilco. Ciudad de México, México. Código Postal: 09030. avilaodin@gmail.com. 
Sumak Qamaña versus indianismo-katarismo. Una disputa ideológica por el proyecto político de nación en Bolivia - Odin Ávila Rojas

Latin American indigenous question, namely indianism (and katarism) and indigenism. These perspectives have a different historical starting point to ideologically understand indigenous people as political subjects in complex and contradicting contexts within contemporary capitalism and its neoliberal stage.

Keyswords: indianism-katarism; ideology; Sumak Qamaña; hegemony; policy

A partir del ascenso de Evo Morales a la presidencia de Bolivia en 2006, comienza una disputa interna por la producción ideológica de discursos comunes que incorporen las identidades ancestrales indígenas con las expresadas durante las "Guerras del Agua y Gas", 2 al igual que aquellas subalternizadas por la colonización occidental. Dicha pugna es parte de la "hegemonización" (Gramsci, 1975:335) que sucede en una nación abigarrada como la boliviana. En esta lucha ideológica pueden ubicarse dos visiones de restructuración del pensamiento y práctica de lo indio: el Vivir Bien o el Sumak Qamaña, y por otro lado, el indianismo-katarismo. Ambas a su vez, corresponden a maneras distintas de leer los procesos de plurinacionalización en base a la posición que ocupan los sujetos en la compleja relación de mando-obediencia coetánea.

Cabe señalar que el Vivir Bien corresponde más al sustento ideológico de la "superficie" plurinacional, mientras el indianismo-katarismo trata de reactivar sus discursos desde los "subsuelos" (Tapia, 2008: 95-97) de la lucha social, en especial, en La Paz y El Alto. Por lo tanto, puede detectarse en las dos visiones mencionadas una mutua tensión entre sí, porque reflejan el proceso histórico hegemónico resultado de las movilizacio-

2 La "Guerra del Agua" se dio en los primeros meses del 2000 y la "Guerra del Gas" en el mes de octubre del 2003. Ambos conflictos movilizatorios representaron la apertura a un nuevo horizonte democrático para cada parte de la sociedad boliviana, en especial, aquellas poblaciones mayoritariamente indígenas que históricamente han tenido una condición colonizada frente a la modernidad occidental de la política y el capitalismo. (Ceceña, 2005: 208 y Gilly, 2009: 25-41). 
nes de la última década por la búsqueda de la autodeterminación nacional.

$\mathrm{Al}$ aclararse en este trabajo, la hegemonía refiere a la redefinición de las relaciones estatales, fuerzas políticas y recomposición de clases sociales en una condición de dinámica de la sociedad. Aquí los sujetos integrantes de la dimensión subterránea y la institucional dominante participan constantemente en la formulación del poder político. Por supuesto, esto incluye las contradicciones internas que se generan en un momento de tránsito de la emancipación hecha por una multiplicidad de hombres y mujeres a su ordenamiento político. Al respecto, Carlos Marx ${ }^{3}$ plantea que los antagonismos y cualquier contradicción en general, mientras estén determinadas por la lógica del valor de intercambio, al igual que la "política del capital" (Ávalos y Hirsch, 2007:235), se acentuarán e incluso nacerán nuevas formas de explotación, dominación y deshumanización, aun en contextos de liberación colectiva.

Ahora bien, ¿quiénes son los hombres y mujeres que respaldan sus acciones en estos planteamientos?; ¿en el fondo hay una lucha interna por quién y cómo debe materializarse la consumación de los logros conseguidos por las movilizaciones indígenas del 2000 al 2005?; ¿hasta qué punto son opuestos un discurso con respecto al otro?; ¿si el Vivir Bien tiene mayor fuerza política en el momento hegemónico actual? Y por último; ¿si los indianista-kataristas tienen la capacidad de proponer un proyecto alternativo para dirigir la plurinacionalización? Las anteriores preguntas se traducen en los siguientes apartados: 1) Vivir Bien o Sumak Qama$\tilde{n} a$. Entre el mito y la institucionalidad dominante; 2) la emergencia subterránea del indianismo-katarismo, y Conclusiones: dos miradas opuestas de comprender la lucha indígena actual.

3 A pesar que hay una visión generalizada de analizar la obra El Capital en términos económicos, aquí se hace un esfuerzo por entenderla desde la teoría política. Por lo tanto, se comprende el capitalismo como relaciones políticas y sociales. (Marx, 1979:382) 
Sumak Qamaña versus indianismo-katarismo. Una disputa ideológica por el proyecto político de nación en Bolivia - Odín Ávila Rojas

\section{1) Vivir Bien o Sumak Qamaña. Entre el mito y la institucionalidad dominante}

Sumak Qamaña o Vivir Bien en su traducción al español, es una palabra polisémica de origen aymara que fue rastreada primero por David Choquehuanca y luego, retomada por el evismo con fines hegemonizantes e ideológicos estatales. ¿Qué significa esto?, el proyecto de plurinacionalización boliviano se ha visto en la necesidad de fomentar la edificación de una dimensión ideológica que permita crear un efecto de legitimación entre los múltiples sujetos sociales y la emergente institucionalización indígena. Tal fenómeno, precisamente, corresponde a los objetivos del "Programa indigenista estatal", ${ }^{4}$ el cual consiste en ejecutar políticas en términos públicos que integren la movilización social hacia los asuntos comunes por medio de la administración del Estado, cuya condición está en vías de construcción.

Por un lado, hablar del Vivir Bien es adentrarse a una parte de las riquezas filosóficas del mundo andino y por otro, implica comprender sus usos políticos que han sido dirigidos hasta el momento por el evismo. El Sumak Qamaña, de ser un concepto perteneciente en origen a la cosmovisión aymara, llega a ser traducido como un discurso ideológico hegemonizador, es decir, busca articular a cada uno de los sectores urbanos y rurales con base a los siguientes "principios holísticos" ${ }^{\prime 5}$ planteados por Choquehuanca:

4 Refiriéndose al conjunto de políticas sociales para incluir a la sociedad india en los asuntos públicos y decisorios desde la institucionalidad dominante. (García, 2011: 75).

5 Los principios del Sumak Qamaña se encuentran dispersos y al mismo tiempo estructurados en la oralidad comunitaria en el altiplano andino. Varios de estos fundamentos son recogidos y desarrollados por intelectuales bolivianos; aunque no todas las lecturas se hacen desde el mismo seno comunal, hay un cierto reflejo de la cosmovisión aymara (principalmente) y quechua en estos. La idea es mostrar aquellos elementos clave que comparten tantos la visión intelectual como la comunitaria sobre esto. Lo anterior puede revisarse en la entrevista al ministro de Relaciones Exteriores de Bolivia (Choquehuanca). 
a) Aceptar las diferencias, quiere decir, respetar las semejanzas y las heterogeneidades entre cada uno de los seres que comparten el mismo planeta. Aquí no hay una relación de subordinación de la naturaleza frente a las sociedades humanas, al contrario, se encuentran las dos partes en diálogo mutuo, porque conllevan una construcción recíproca de la totalidad social. Este principio conecta la diversidad cultural y cosmogónica de los sujetos con sus expresiones políticas.

b) Priorizar los derechos de la Pachamama. Significa reivindicar los derechos de la Madre Tierra (Pachamama en aymara) para así poder defender los derechos humanos. La idea de humanidad está relacionada con la conciencia que tienen los hombres y mujeres sobre el cuidado de los elementos que constituyen la naturaleza, es decir, la vida social tiene como obligación respetar a cada uno de los seres con quien comparte territorio.

c) Saber comer y beber, es disfrutar con plenitud las comidas a partir de las estaciones del año (alimentos según la época). Acompañado de saber beber alcohol con moderación para acompañar los alimentos. En las comunidades indígenas, cada fiesta tiene un significado y el alcohol está presente en la celebración, pero se consume sin exagerar o lastimar a alguien. Esta consigna debe regirse con base en la práctica de los ancestros que se alimentaban con un determinado producto durante toda una estación, con la intención de garantizar la salud a un nivel comunitario.

d) Saber danzar, se relaciona con algunos hechos concretos como la cosecha o la siembra. Las comunidades continúan honrando con baile y música a la Madre Tierra, principalmente en épocas agrícolas; sin embargo, en las ciudades las danzas originarias son consideradas como expresiones folclóricas, pero a pesar de eso tienen un gran impacto simbólico en la reconstitución comunitaria. 
Sumak Qamaña versus indianismo-katarismo. Una disputa ideológica por el proyecto político de nación en Bolivia - Odín Ávila Rojas

e) Saber trabajar y reciprocidad es considerar el trabajo como fiesta. El trabajo es felicidad y el motor comunitario. A diferencia del capitalismo, donde se paga por trabajar, en el nuevo modelo se retoma el pensamiento ancestral de considerar el trabajo como una fiesta. Es una forma de crecimiento y de integración comunitario-indígena; por eso en las culturas aymaras se trabaja desde pequeños. No en un sentido valorizante, sino más bien en uno intersubjetivo.

f) Retomar el Abya Yala, protección de las semillas y la recuperación de la agricultura. Abya Yala quiere decir promover que los pueblos se unan en una gran familia. Esto implica que todas las regiones del país se reconstituyan en lo que ancestralmente se consideró como una gran comunidad. Al establecerse así, la relación entre lo que puede ser un territorio y el poder constituidor de este. Por supuesto, esto implica la reincorporación de la agricultura a las comunidades como actividad de politización y estrechamiento de vínculos sociales. Se parte de esta doctrina para recuperar las formas de vivencia en comunidad, como el trabajo de la tierra, el cultivo para cubrir las necesidades básicas de la subsistencia.

g) Saber comunicarse, interactuar y escuchar a los mayores en las comunidades andinas. Se pretende retomar la comunicación que existía en las comunidades indígenas con las dimensiones ancestrales. El diálogo se plantea como el resultado de esta buena comunicación, como antes lo hacían los viejos aymara-quechuas con la sociedad, para resolver los problemas sin que se presenten conflictos más graves. Escuchar a los mayores es leer las arrugas de los abuelos para poder retomar el camino.

h) El Vivir Bien no es "vivir mejor" porque es contrario a la lógica del capital y Occidente, al sustentar sus preceptos en el mundo andino, tales como la reciprocidad, el respeto a la mujer, al anciano, etc. Para la nueva doctrina, vivir mejor se 
traduce en egoísmo, desinterés por los demás, individualismo y solamente pensar en el lucro. Considera que la doctrina capitalista impulsa la explotación de las personas para la captación de riqueza en pocas manos, mientras que el vivir bien apunta a una vida sencilla que mantenga una producción equilibrada.

i) Recuperación de recursos naturales para ejercer la soberanía de los pueblos aymara-quechuas. El objetivo es tomar la riqueza natural del país y permitir que todos se beneficien de ésta en términos equilibrados y equitativos. La finalidad del Vivir Bien también incluye la nacionalización y recuperación de aquellos recursos estratégicos que alimentan la prosperidad social en contraposición con una explotación irracional de la naturaleza. Luego entonces, es construir desde las comunidades el ejercicio de la soberanía boliviana por medio del consenso comunal que defina una unidad y la responsabilidad a favor del bien común, sin que nadie falte. Muestra de ello es distribuir racionalmente el agua y aprovecharla de manera correcta.

Ahora bien, vale la pena hacer un esfuerzo por ver si dichos principios del Sumak Qamaña, más allá de corresponder a una dimensión lingüística y filosófica de la cultura andina, en especial la aymara, llegan a ser practicados en la cotidianidad, por parte de la sociedad contemporánea indígena en Bolivia. La cuestión es analizar si el Vivir Bien tiene algún grado de conexión histórica con la cosmovisión de los pueblos en el Altiplano o tan solo es una formulación intelectual indígena inspirada en ciertos elementos culturales ancestrales con usos hegemónicos a cargo del evismo. Por lo tanto, debe analizarse la forma en que es usado tal discurso para legitimar el mando de quienes tratan de controlar la disputa por la plurinacionalización.

Debe recordarse que el evismo conforme el transcurrir de los años ha constituido su propia fuerza política y se ha visto en la urgente necesidad de crear una ideología que sostenga el 
Sumak Qamaña versus indianismo-katarismo. Una disputa ideológica por el proyecto político de nación en Bolivia - Odín Ávila Rojas

"mito" ${ }^{\prime \prime}$ del Estado frente al resto de sujetos, organizaciones, movimientos, al igual que las distintas partes de la totalidad social. La mitificación estatal tiene la primordial función de generar un imaginario que pueda ser asimilado directa o indirectamente por quienes tratan de reorganizar la voluntad colectiva. Para así, poder proyectar un nuevo ordenamiento político que tenga legitimación social. En Bolivia, esto ha significado la redefinición de aquellas relaciones sociales, fuerzas políticas y múltiples determinaciones históricas con base en el simbolismo de la memoria, identidad y cosmovisión alrededor de lo indio.

Si bien, el Vivir Bien surge bajo una formulación intelectual aymara, también es pensado como un elemento de la forma andina de interpretación del universo que trata de ser traducida en clave ideológica estatal plurinacional. En este sentido, el Sumak Qamaña corresponde a una etapa de la hegemonía que necesita usar un discurso que pueda tener enlazar el mando evista con la potencia que emana de una voluntad compleja en continua organización, movilización y cuestionadora de su propia forma política.

En términos de Nicolás Maquiavelo, sería la confrontación por definir la estructura del pensamiento que tendrá el nuevo "Príncipe" (Maquiavelo, 1993; 111 y Roux, 2005; 264), quien por cierto en los tiempos modernos, vale la pena preguntarse: ¿cuál es su forma y reactualización política?, porque no encarna en un solo individuo, sino más bien en una organización política. La cual puede impulsarse por un partido político en sus distintos modelos históricos o puede derivarse de los intensos flujos movilizatorios colectivos. Precisamente éste es el caso boliviano del siglo XXI, en el cual la figura del redentor tiene una dirección emancipadora o por lo menos, así ha sido planteado en el contexto de la lucha por la descolonización a nivel nacional.

6 En términos de memoria, voluntad, deseos e imaginarios colectivos. 
Según el teórico clásico italiano: "cuando un simple ciudadano, no por medio de crímenes u otras intolerables violencias sino con el favor de sus conciudadanos llega a príncipe de su patria... el principado es creado por el pueblo" (Maquiavelo, 1993:38). Al considerar Maquiavelo así, la posibilidad de elegir a quien se hará cargo del mando político a través de la esfera social. Más adelante él mismo dice: "el pueblo, a su vez, viendo que no puede resistirse a los grandes, acrecienta la reputación de alguien y lo convierte en príncipe para defenderse con su autoridad" (Maquiavelo, 1993:38).

Con referencia a los párrafos anteriores, la lectura de Antonio Gramsci que alude a Maquiavelo, expone la siguiente idea: "el moderno príncipe, el mito-príncipe, no puede ser una persona real, un individuo concreto; solo puede ser un organismo, un elemento de sociedad complejo en el cual comience a concretarse en una voluntad colectiva reconocida y afirmada parcialmente en la acción. Este organismo ya ha sido dado por el desarrollo histórico y es el partido político" (Gramsci, 1975: 28). En este sentido el Vivir Bien alude a la formación ideológica de la refundación estatal que vive Bolivia, por eso el interés de darle un uso discursivo de normalización de la acción política a éste.

El príncipe tiene un rostro simbólico indígena que se encuentra en constante pugna, al igual que expresa una suerte de síntesis política, la cual es la redefinición de las voluntades producidas por las dinámicas de quienes participan en el largo proceso hegemónico boliviano. Debe recordarse que la dimensión hegemónica de un pueblo es conformada mediante la dialéctica entre la sociedad civil y la sociedad política que circulan en ella. Tal relación puede derivar en la concentración del mando político en determinados espacios institucionales o puede llevar a la ampliación del proyecto estatal.

Durante este proceso, el Sumak Qamaña se visualiza desde la esfera dominante de la política, sin incorporar aquellos elementos ideológicos indianistas que históricamente integran la memo- 
Sumak Qamaña versus indianismo-katarismo. Una disputa ideológica por el proyecto político de nación en Bolivia - Odín Ávila Rojas

ria boliviana social y rebelde. Por esta razón, el Vivir Bien y el indianismo-katarismo, además de ser discursos planteados en distintos lugares de la topografía política indígena, derivan en un antagonismo mutuo, es decir, son opuestos uno con respecto al otro.

\section{2) La emergencia subterránea del indianismo- katarismo}

El indianismo-katarismo puede comprenderse como un importante esfuerzo contemporáneo de articulación ideológica de dos grandes corrientes históricas de la lucha indígena del siglo XX: el indianismo y por otro lado; el katarismo. Ambas influyeron en diversas organizaciones político-sociales que intentaron reproducir la forma comunitaria de la política aymara-quechua no nada más en niveles locales, sino también nacionales. Si bien, una corriente con respecto a la otra comparte rasgos comunes de memoria, trayectoria rebelde e identidad andina, al mismo tiempo, tienen diferencias notables entre sí, porque responden a momentos específicos de comprensión sobre ¿qué significa políticamente ser indio?; ¿cómo traducir este pensamiento en estrategias descolonizadoras del capital y la política occidental moderna?

Por ejemplo: el indianismo de manera formal aparece aproximadamente una década después de la "Revolución nacional de 1952" (Zavaleta, 2008: 212) con la fundación del Partido de Indios Aymaras y Keswas (PIAK) a cargo de Fausto Reinaga, este último además de ser impulsor de la estructura partidista, ha sido el principal referente ideológico de la corriente indianista. Cabe señalar, el PIAK en 1966 cambia su nombre a Partido Indio de Bolivia (PIB), por ello, el mismo Reinaga considera el "15 de enero de 1962" como la fecha de nacimiento del PIB.

Las ideas indianistas en gran medida están contenidas en la obra de Reinaga, quien plantea una concepción descolonizadora del sujeto indígena al visualizarlo bajo sus propios términos 
de potencia histórica. Por esta razón, el pensador boliviano dice: "al subjetivismo europeo oponemos el realismo indio" (Reinaga, 1971:145). Este planteamiento hace una crítica a aquellos modelos occidentales de verdad, moralidad y eticidad que juzgan de manera negativa a las sociedades y culturas del planeta Tierra que no son iguales a ellas, ni siguen los preceptos modernos del supuesto progreso capitalista. Desde luego, es necesario indicar que no todas las teorías político-sociales de Europa reproducen o son estructuradas de acuerdo a estos paradigmas.

Según Reinaga (1971), el pensamiento del indio debe emanar del mismo, porque solo así, puede dirigir su proceso de empoderamiento de aquellas formas comunitarias de la política y lo social que han quedado subordinadas e incluso ocultas a consecuencia del orden dominante colonial, cuyo inicio fue con las expediciones españolas de Francisco Pizarro en el siglo XVI. Por lo tanto, el indianismo es una corriente ideológica que une elementos de la cosmovisión aymara-quechua con los anhelos de los sujetos indios en vías de recobrar su oportunidad para organizar la liberación final de la nación andina Qullasuyu.

Hablar de indianismo es pensar en la revolución del sujeto indígena desde su propia condición y realidad. Reinaga al respecto expresa: “...el indio desea y quiere su liberación; liberación como pueblo, como nación, como raza y como cultura; el indio tiene que hacer su política. Y no puede hacer su política, si no cuenta con un partido propio, con su partido..." (Reinaga, 1971: 110). Aquí el ideólogo aymara manifiesta una crítica al modelo partidista eurocéntrico de las izquierdas, al igual que las estrategias de lucha planteadas desde el marxismo-leninismo boliviano de las décadas de los cincuenta, sesenta y setenta de la anterior centuria. Dicho cuestionamiento obedece a un reposicionamiento de quienes integran la sociedad andina en su fundamento cultural $\mathrm{y}$ ancestral.

$\mathrm{Al}$ interior de las ideas indianistas, específicamente en el caso de Reinaga, puede localizarse una discusión ontológica inclui- 
Sumak Qamaña versus indianismo-katarismo. Una disputa ideológica por el proyecto político de nación en Bolivia - Odín Ávila Rojas

da en lo ideológico con fines de convocar a la organización de la politización india, sin préstamos identitarios de los modelos exportados del Occidente moderno. Por eso, se plantea una reactualización de la emancipación como un proceso que impulsa la indianización del indígena. Desde luego, con sustento en la interpretación de la cosmovisión y cultura andina para estructurar un proyecto político con eco nacional.

Mientras el indianismo nace en una dimensión intelectual de la discusión indígena, el katarismo empieza a existir en la provincia de Aroma como una corriente de opinión motivada por la juventud aymara que vivió en la década de los setenta del siglo pasado. Para luego así, pasa a convertirse en un movimiento político e ideológico reivindicador de la rebelión de Tupak Katari, acontecida en los años de 1781-1783. Los kataristas son un esfuerzo organizativo por enfrentar los vaivenes de la lógica liberal moderna de la política boliviana. Pero no nada más se quedó en eso, también en paralelo, fue una estrategia para insertarse al sistema democrático liberal, y a partir de ahí poder refuncionalizar la lucha india.

Según Javier Hurtado: "los kataristas, con mucho instinto, no se marginaron de las estructuras comunitarias, tanto de la organización tradicional como la sindical" (Huertado, 1986: 40). Para éstos, la estrategia de lucha se concentró en la creación de sindicatos urbanos y campesinos, al igual que la combinación de ambas expresiones gremiales. Debe recordarse que la visión occidental moderna de sindicalismo contrasta con la entendida por los pueblos aymaras y quechuas, porque si bien, para la clase trabajadora y explotada plantear la defensa de derechos laborales ha sido una meta histórica vital, por lo menos en los últimos siglos, por otro lado, la perspectiva indígena observa en los organismos sindicales, más que un fin, una especie de vehículos políticos que permiten transportar sus códigos en los campos de disputa por la hegemonía a nivel nacional.

Al respecto, Silvia Rivera Cusicanqui (2003): 
“el movimiento katarista fue desde sus inicios una corriente ideológica en la que se sintetizaban temas culturales, proyecciones políticas y lucha reivindicativas. Fue también, como ya se señaló, un movimiento con expresiones tanto urbanas como rurales, siendo las primeras de vital importancia en la elaboración y sistematización de las ideas y programas del movimiento. Contenía, pues, una multiplicidad de matices y de percepciones colectivas, que permanecieron relativamente indiferenciadas durante el periodo de lucha clandestina y que solamente serían esbozadas en sus documentos públicos. Así, en el Manifiesto de Tiwanaku se hablaba de luchar por la renovación del sindicalismo, al tiempo que se señalaba la necesidad de construir una organización política propia, capaz de representar autónomamente los intereses del campesinado del país" (p. 163).

Precisamente, los kataristas responden a la necesidad de organizarse con sustento en una identidad clasista. Con el objetivo de incidir en aquellos espacios políticos determinados por el liberalismo boliviano. Los cuales por cierto, habían quedado pendientes o poco contemplados por los indianistas. En este sentido, el katarismo puede leerse como una estrategia de liberación a partir de la adaptación de los indios en el mestizaje de la sociedad moderna y capitalista. Muestra de esto, fue la creación a finales de los setenta del "Movimiento Revolucionario Tupak Katari (MRTK), el Movimiento Indio Tupak Katari (MITKA), la Confederación Sindical Única de Trabajadores Campesinos de Bolivia (CSUTCB)" (Pacheco, 1992: 395) y otros organismos indígenas de politización que ubicaron sus maniobras militantes con relación a los métodos marxista-leninistas de la pasada centuria.

Aunque no nada más los modelos sindicales fueron usados por los kataristas, porque más adelante, hubo una diversidad de expresiones que desembocaron en los formatos guerrilleros, pero también en algunos casos, fueron cooptados por los partidos libe- 
Sumak Qamaña versus indianismo-katarismo. Una disputa ideológica por el proyecto político de nación en Bolivia - Odín Ávila Rojas

rales y sus rutas de participación política. El “Ejército Guerrillero Tupak Katari (EGTK)" (Iturri, 1995:137) a finales de los ochenta y principios de los noventa, representó un esfuerzo por organizar en términos comunitarios al campesinado boliviano mediante la vía armada; mientras algunos exkataristas decidieron entrar al juego del neoliberalismo, entre los que sobresale, Víctor Hugo Cárdenas.

Desde luego, entre la forma comunitaria indígena de hacer política y la estrategia de las izquierdas tradicionales de ese entonces, había una tensión clara, la cual en cierta medida era interpretada por los aymaras y quechuas como una oportunidad para darle vigencia a sus códigos identitarios bajos vestimentas participativas que les permitieran insertarse en la pelea para conseguir un lugar en la representatividad del sistema democrático liberal dominante. Debe señalarse que las prácticas de los pueblos andinos se caracterizan por ser reproducidas en contextos complejos y adversos a ellas. Dicho en otras palabras, los indígenas a través del tiempo, han hecho suyas las estructuras organizativas que creen adecuadas para su desarrollo social.

Precisamente, los kataristas llevaron las dinámicas y prácticas de los pueblos del Altiplano boliviano a la dimensión sindical. Tales códigos comunales son: "la obligatoriedad, rotatividad, reciprocidad, complementariedad" (Mamaní, 2010:206 y Gutiérrez, 2009: 382) y, en general, un sentido de autorregulación colectiva de ejercer la relación mando-obediencia. Por ejemplo, no hay rotación de cargos, sin la obligación de sus representantes para cumplirlos efectivamente, porque la autoridad se sujeta a los lazos de restitución social y viceversa. El katarismo entonces, se definió por tener una recuperación de la memoria, cultura y politización indígena, a la vez de potencializarlas a través de las identidades del obrero y el campesino con fines de transformación descolonizadora.

Ahora bien, el indianismo-katarismo al ser un horizonte ideológico en formación a partir de la articulación tanto de las 
corrientes indianistas como las kataristas, plantea la reconstitución política de Katari, Sisa y lo indio, en contraste a la visión indigenista folclórica instituida por el evismo. Aquí, no se da por hecho consumado la plurinacionalización, ni tampoco el punto de partida es la antonomasia estatal, más bien, se trata de proponer un eje que amplíe la panóptica histórica de la lucha social y su conexión con ese largo proyecto político que significa la reconstitución territorial del Qullasuyu.

Los sujetos identificados con las ideas indianista-kataristas creen que todavía la autodeterminación de la nación está en una disputa entre movimientos sociales e instituciones formales a cargo del evismo. Según el indianismo-katarismo, las fuerzas que fueron producidas a lo largo del proceso revolucionario de los primeros años del siglo XXI, ahora han derivado en fuerzas institucionalistas dominantes, las cuales han impuesto una estrategia normalizadora de la acción colectiva, sin considerar el consenso del resto de organizaciones y colectividades que contribuyeron a la victoria indígena a nivel nacional. Y que ahora, pueden participar en la toma de decisiones del orden plurinacional.

No debe olvidarse, la reactualización indianista-katarista que tiene su estructuración el 14 de noviembre de 2006 con la Declaración de Qharqha Marka en Peñas (provincia de La Paz), una declaración que hace una convocatoria para tratar de poner a discusión en el vigente siglo, aquellos antiguos documentos de origen indianista provenientes de las décadas de los setenta y ochenta. Tales como La Declaración de Tiwanaku de 1973 y la Tesis India de 1970. Pero también, propone integrar referencias enunciativas recuperadoras de la rebeldía india de principios de este siglo. Ejemplo de esto último son la Declaración de Achacachi en el 2000 y luego, el Manifiesto de Achacachi en el 2001.

En el actual entorno político boliviano, quienes motivan el proceso de articulación ideológica del indianismo-katarismo son sujetos caracterizados por su activismo y en casos deter- 
Sumak Qamaña versus indianismo-katarismo. Una disputa ideológica por el proyecto político de nación en Bolivia - Odín Ávila Rojas

minados, por su larga trayectoria militante al interior de varios organismos político-sociales. Estos hombres y mujeres se encuentran dispersos en movimientos, organizaciones y pequeños núcleos de intelectualidad indígena, es decir, no hay propiamente una conglomeración de ellos en una agrupación determinada, sino más bien están distribuidos en las distintas expresiones de lucha social crítica al capitalismo neoliberal, la colonización y la institucionalización de la plurinacionalización. Esto explica por qué es más preciso hablar de un horizonte ideológico común indianista-katarista, que solamente de casos específicos organizativos.

\section{Conclusiones: dos miradas opuestas de comprender la lucha indígena actual}

La relación entre el indianismo-katarismo y el Vivir Bien se define por ser una suerte de síntesis ideológica, en la cual se reflejan las contradicciones internas producidas en el desarrollo del nuevo orden plurinacional. Debe recordarse, el acto de sintetizar en términos de análisis político implica hacer una selección de acontecimientos, procesos, memorias e historicidades que pueden o no reconstruir los contenidos y significados político-sociales de una nación. Por supuesto, la sintetización significa crisis y recomposición, es decir, las clases sociales, tienen un posicionamiento distinto al que tenían en las dinámicas hegemónicas anteriores.

En Bolivia, la hegemonía dominante antes del 2000 correspondía al entramado del "Estado aparente". 7 Después de la Guerra del Agua, los sujetos que caracterizaban las clases dominadas logran debilitar la posición de mando de los grupos neolibera-

7 La tradición zavaleteana dice que un Estado aparente es aquel constituido de manera artificial por una clase, elite o grupos institucionalizados. Aquí no hay una formación popular-nacional, ni tampoco una articulación de lo político desde lo social (Zavaleta, 2008: 212). 
les en el gobierno a través de su lucha popular. A tal grado de hacer descender a Sánchez de Lozada y a esa gran parte de la institucionalidad que operaba en función suya. Para así, a finales de 2005 y principios de 2006 impulsar la presidencia de Morales como representación de un cambio de flujo de fuerzas políticas, al igual que la posibilidad de plantear un horizonte descolonizador. La nación boliviana, sin duda pasó de un Estado aparente a un larguísimo proceso todavía abierto de reconstrucción política nacional.

Razón por la cual, la disputa por ese horizonte interior ha provocado que tanto los indianistas-kataristas como los evistas y grupos en el poder político actual, entren en un momento intensificado de disputa para darle forma a la plurinacionalización. Ambas tienen imágenes, identidades, al igual que concepciones distintas y opuestas sobre lo indio. Este fenómeno representa una discusión muy profunda, cuya densidad desde los levantamientos del 2000 hasta el segundo periodo de gobierno evista, todavía no termina. Incluso se ha intensificado, porque hay un lucha por la descolonización interna, específicamente, por la disputa sobre qué tipo de elementos del indio van a traducirse en la ideologización del "Príncipe con rostro indígena".

\section{Bibliografía}

Ávalos, G., y Hirsch, J. (2007). La politica del capital. México: UAM-Xochimilco.

Ceceña, A. (2005). La guerra por el agua y por la vida. Argentina: América Libre-Ediciones Madres Plaza de Mayo-CDAVC.

Choquehuanca, David, "25 Postulados para Entender el Vivir Bien", en; http://indigenaslibertarios.blogcindario.com/2010/02/0005525-postulados-para entender-el-vivir-bien entrevistacon-davidchoquehuanca-bolivia.html.

García, A. (2011). Las tensiones creativas de la revolución. La quinta fase del Proceso del Cambio. La Paz: Ediciones de la Vicepresidencia del Estado Plurinacional-Presidencia de la Asamblea Legislativa Plurinacional. 
Sumak Qamaña versus indianismo-katarismo. Una disputa ideológica por el proyecto político de nación en Bolivia - Odín Ávila Rojas

Gramsci, A. (1975). Cuadernos de la cárcel: notas sobre Maquiavelo, sobre política y sobre el Estado Moderno, Tomo I. México: Juan Pablo editores.

Gutiérrez, R. (2009). Los ritmos del Pachakuti: levantamiento y movilización en Bolivia (2000-2005). México: BUAP-Bajo Tierra-Sísifo Ediciones.

Gilly, A. (2009). Historias clandestinas. México: Ítaca-La Jornada.

Hurtado, J. (1986). El katarismo. Bolivia: Hisbol.

Iturri, J. (1995). EGTK: La Guerrilla aymara en Bolivia. Bolivia: Ediciones Vaca Sagrada.

Mamani, V. (2010). Ritos espirituales y prácticas comunitarias del aymara, Bolivia, Creart impresores.

Marx, C. (1979). El Capital. Tomo 1/Vol 1. México: Siglo XXI.

Maquiavelo, N. (1993). El Príncipe. España: Altaya.

Pacheco, D. (1992). El indianismo y los indios contemporáneos en Bolivia. Bolivia: HISBOL-MUSEF.

Reinaga, F. (1971). Tesis india. Bolivia: Ediciones PIB.

Rivera, S. (2003). Oprimidos, pero no vencidos: luchas del campesiando aymara y quechwa, 1900-1980. Bolivia: THOA.

Roux, R. (2005). El príncipe mexicano. Subalternidad, historia y Estado, México: Ediciones Era.

Tapia, L. (2008). Política salvaje. Bolivia: CLACSO-Muela del Diablo Editores-Comuna.

Zavaleta, R. (2008). Lo nacional-popular en Bolivia. Bolivia: Ediciones Plural. 